2012

\title{
Depression, Anxiety, and Symptom Profiles Among Female and Male Victims of Sexual Violence
}

Ekta Choudhary

Merideth Smith

Robert M. Bossarte

Follow this and additional works at: https://researchrepository.wvu.edu/faculty_publications

\section{Digital Commons Citation}

Choudhary, Ekta; Smith, Merideth; and Bossarte, Robert M., "Depression, Anxiety, and Symptom Profiles Among Female and Male Victims of Sexual Violence" (2012). Faculty Scholarship. 117.

https://researchrepository.wvu.edu/faculty_publications/117 


\title{
American Journal of Men's Health
}

http://jmh.sagepub.com/

\section{Depression, Anxiety, and Symptom Profiles Among Female and Male Victims of Sexual Violence}

Ekta Choudhary, Merideth Smith and Robert M. Bossarte

Am J Mens Health 2012 6: 28 originally published online 21 November 2011

DOI: $10.1177 / 1557988311414045$

The online version of this article can be found at:

http://jmh.sagepub.com/content/6/1/28

\author{
Published by: \\ (SAGE \\ http://www.sagepublications.com
}

Additional services and information for American Journal of Men's Health can be found at:

Email Alerts: http:/jjmh.sagepub.com/cgi/alerts

Subscriptions: http://jmh.sagepub.com/subscriptions

Reprints: http://www.sagepub.com/journalsReprints.nav

Permissions: http://www.sagepub.com/journalsPermissions.nav

>> Version of Record - Jan 10, 2012

OnlineFirst Version of Record - Nov 21, 2011

What is This? 


\title{
Depression, Anxiety, and Symptom Profiles Among Female and Male Victims of Sexual Violence
}

\author{
Ekta Choudhary', Merideth Smith', and Robert M. Bossarte ${ }^{1,2}$
}

\begin{abstract}
Sexual violence is a serious public health problem that has been associated with negative mental and physical health outcomes. Few existing studies have examined the prevalence and patterns of adverse mental health among victims of sexual violence using data from nationally representative samples of U.S. adults. The main objectives of this study were to identify patterns in the associations between sexual violence victimization and depression and anxiety (DA) symptoms using data from the sexual violence and DA Behavioral Risk Factor Surveillance System (BRFSS) modules. Stratified multivariate logistic regression models were conducted to test the associations between sexual violence victimization and DA controlling for demographic characteristics. Multiple stratified MANOVA models were used to detect the effect of sexual violence victimization on DA symptoms while controlling for key demographic characteristics. Among all 61,187 participants, more than $5 \%(n=3,240)$ were victims of sexual violence, out of which $18.82 \%$ reported being diagnosed with depression, $8.37 \%$ reported an anxiety disorder, and $28.28 \%$ reported being diagnosed with DA disorder.Victims of sexual violence reported significantly higher number of days when they had trouble concentrating, sleep difficulties, poor appetite, little interest or pleasure in activities, blamed themselves for personal failure, felt depressed, and had little energy. The present study highlights the importance of collecting nationally representative data from victims of sexual violence and extends previous findings from clinically based studies. This study also serves as an example of an analytic approach that addresses a public health priority area by drawing on data from multiple topic-specific BRFSS modules.
\end{abstract}

\section{Keywords}

sexual assault, depression, anxiety, mental health, male victims

\section{Introduction}

Sexual violence is a serious public health problem that has been associated with long-lasting negative mental and physical health outcomes (Choudhary, Coben, \& Bossarte, 2008; Norris \& Feldman-Summers, 1981; Resick, 1993; Walker, Archer, \& Davies, 2005a). In 2007, the last year for which data are available, results from the National Crime Victimization Survey indicate that an estimated 248,300 women and men were victims of rape or other forms of sexual assault (Rand, 2008). Estimates from a nationally representative sample of U.S. adults suggest that as many as 1 in 6 females and 1 in 33 males experience some form of sexual violence during their lifetime (Tjaden \& Thoennes, 2006). However, studies that have estimated the prevalence of male sexual violence victimization have produced conflicting results, with estimates ranging from $0.6 \%$ to $22.2 \%$ depending on the study sample, notably lower than estimates of female victimization calculated using comparable data (Tewksbury, 2007; Tjaden \& Thoennes, 2006).

An emerging body of research is establishing a strong association between sexual violence victimization and poor mental health (Hedtke et al., 2008; Kaminer, Grimsrud, Myer, Stein, \& Williams, 2008; Mechanic, Weaver, \& Resick, 2008; Rentoul \& Appleboom, 1997; Ullman, Filipas, Townsend, \& Starzynski, 2007; Walker, Archer, \& Davies, 2005b) that may differ for women and men (Afifi et al., 2009; Reid et al., 2008), and results from previous studies have suggested that sexual violence

\footnotetext{
'West Virginia University Injury Control Research Center, Morgantown, WV, USA

${ }^{2}$ University of Rochester, Rochester, NY, USA
}

Corresponding Author:

Robert M. Bossarte, Department of Psychiatry, University of Rochester, 300 Crittenden Blvd., Box PSYCH, Rochester, NY 14262, USA Email: robert_bossarte@URMC.rochester.edu 
victimization can affect mental and physical health across the life course (Leserman, 2005; Messman-Moore, Brown, \& Koelsch, 2005; Santiago, McCall-Perez, Gorcey, \& Beigel, 1985). For example, victims of sexual assault have been shown to be at an increased risk for posttraumatic stress disorder (PTSD), depression, and anxiety disorders (Messman-Moore et al., 2005; Santiago et al., 1985). Results from a nationally representative sample of U.S. adults indicated that $33 \%$ of female and $24.2 \%$ of male victims of sexual violence received counseling for adverse mental health outcomes as a result of their most recent victimization (Tjaden \& Thoennes, 2006). However, research among female victims of rape suggests that as much as $40 \%$ of all victims may never seek professional help for mental health problems (Amstadter, McCauley, Ruggiero, Resnick, \& Kilpatrick, 2008). Despite lower than expected levels of mental health service utilization, existing studies have suggested that symptoms of depression and anxiety disorders are prevalent among both men and women who were victims of sexual violence (Fergusson, Swain-Campbell, \& Horwood, 2002; Norris \& FeldmanSummers, 1981).

Results from studies examining symptom severity and clinical presentation using samples of females obtained from clinical settings have suggested that symptom severity, for diagnoses such as depression or PTSD, are strongly associated with sexual violence victimization (Cortina \& Kubiak, 2006; Schwartz, 1991) and may be more pronounced than similar symptoms among victimized males. However, findings from studies of male victims of sexual violence suggest that $97 \%$ of male victims reported experiencing feelings of depression and $92 \%$ reported feelings of anxiety (Walker et al., 2005a). Population-based studies have also suggested a strong association between recent (within the last 12 months) and distant (lifetime) sexual violence victimization and adverse mental health indicators among both males and females (Choudhary et al., 2008).

Despite an extensive history of research on the prevalence and correlates of sexual violence, few studies have compared gender differences in the prevalence and consequences of sexual violence victimization among members of the general U.S. adult population. The main objectives of the present study were to compare the prevalence of poor mental health among male and female victims of sexual violence and to identify patterns in the associations between victimization and symptoms of depression and anxiety.

\section{Method}

Data were obtained from the 2006 Behavioral Risk Factor Surveillance System (BRFSS) survey, an ongoing data collection program designed to collect data on risk factors and health behaviors using a nationally representative sample of U.S. adults. Detailed information about the questionnaire and data collection process can be obtained from the BRFSS website (http://www. cdc.gov/brfss/; Centers for Disease Control and Prevention [CDC], 2006). Briefly, BRFSS is cross-sectional telephone survey conducted by state health departments. The questionnaire has three parts including a core component used by all states, topic-specific optional modules, and state-added questions. The topic-specific optional modules are supported by the CDC and chosen by the participating state. This study uses data from respondents who responded to the core questionnaire and two optional modules, sexual violence and depression and anxiety modules, which were administered in 11 U.S. states and territories in year 2006. The response rate among participating states ranged from $31.8 \%$ to $58.4 \%$ in 2006 .

\section{Variable Recoding}

Sexual violence victimization was identified using a single question in the BRFSS sexual violence module asking about unwanted sexual intercourse experienced at any point in the respondent's lifetime. The question asked, "Has anyone EVER had sex with you after you said or showed that you didn't want them to or without your consent." The reference group for all analyses was respondents reporting no victimization. Correlates of sexual violence victimization included eight depression and anxiety symptom questions and self-reported diagnosis from a health care professional of a depression and/or anxiety disorder. The eight symptom questions in the depression and anxiety module were similar to those routinely asked as part of the nine-item Patient Health Questionnaire and measured the number of days with symptoms of depression and anxiety over the past 2 weeks (Kroenke, Spitzer, $\&$ Williams, 2001). These symptoms included loss of pleasure, depressed mood, sleep problems, lack of energy, change in appetite, feelings of failure, difficulty concentrating, and feeling slow or agitated. Questions asking about a diagnosis of depression and/or anxiety included the following: (a) "Has a doctor or other health care provider EVER told you that you have a depressive disorder (including depression, major depression, dysthymia, or minor depression)?" (b) "Has a doctor or other health care provider EVER told you that you had an anxiety disorder (including acute stress disorder, anxiety, generalized anxiety disorder, obsessive-compulsive disorder, panic disorder, phobia, PTSD, or social anxiety disorder?" Response options included yes and no. Based on responses to these diagnosis questions, three mutually exclusive outcome categories were created. The first category, "depression only," included those respondents who answered "Yes" to the question asking about a diagnosis of a depressive 
American Journal of Men's Health 6(I)

disorder and answered "No" to the question asking about a diagnosis of an anxiety disorder. The second category, "anxiety only," defined those respondents who answered "Yes" to the question asking about a diagnosis of an anxiety disorder and answered "No" to the question asking about a diagnosis of a depression disorder. The third category "both depression and anxiety" included respondents who answered "Yes" to the diagnosis of both depression and anxiety disorders.

Controls for each regression model included age, gender, marital status, race/ethnicity, income, and education. Age was divided into six categories (18-24, 24-34, 35-44, 45-54, 55-64, and 65+ years). All participants were divided into four main racial/ethnic categories including White, African American, Hispanic, and Others. Marital status included married, unmarried, and divorced or separated categories. Educational attainment was dichotomized into "attended high school or less" and "more than high school education." Annual household income groups were divided into less than $\$ 25,000, \$ 25,000-\$ 50,000$, and above $\$ 50,000$ categories.

\section{Data Analysis}

Stratified multivariate logistic regression models were conducted to test the associations between depression and anxiety disorder diagnoses and sexual violence victimization while controlling for demographic measures and other potential confounders (age, gender, marital status, race/ethnicity, income, and education). To identify genderbased differences in symptoms, all analyses were conducted for the overall sample and stratified by gender. Multivariate analysis of variance (MANOVA) was used to estimate the influence of sexual violence victimization and key demographic variables (age, gender, race/ethnicity, marital status, and education) on depression and anxiety symptoms reflected by the eight symptom questions. Chisquare test of homogeneity was used to identify significant differences between frequencies. All frequencies and regression models were calculated using SAS (Version 9.1) and SUDAAN (Version 9.01).

\section{Results}

In 2006, a total of 61,187 persons participated in the sexual violence and depression and anxiety modules. As shown in Table 1, there were 24,608 male (48.75\%) and 36,579 female (51.25\%) participants. A majority of participants were White $(73.74 \%)$, less than the age of 54 years $(67 \%)$, married (65.56\%), and had more than high school education $(60.26 \%)$ with an annual household income of more than $\$ 50,000$ (46.59\%). Among all participants, 3,240 $(5.3 \%)$ reported sexual violence victimization. A majority of these participants were females $(88.84 \%)$. A com- parison of demographic characteristics and depression and anxiety diagnostic categories among victimized and nonvictimized groups identified several significant differences (see Table 1). Chi-square test of homogeneity results indicated that victims of sexual violence were more likely to be female $\left(88.84 \%, \chi^{2}=502.65, p<.05\right)$ and to have been diagnosed with depression $\left(18.82 \%, \chi^{2}=112.79, p<\right.$ $.05)$, anxiety $\left(8.37 \%, \chi^{2}=25.47, p<.05\right)$, and both depression and anxiety $\left(28.28 \%, \chi^{2}=192.96, p<.05\right)$.

Comparisons of bivariate associations between sexual violence victimization and diagnosis with depression and anxiety disorder are shown in Table 2. Overall, the pattern of associations between sexual violence victimization and categories of depression and anxiety disorder were similar among males and females. When compared with participants who reported no victimization, those who reported victimization were more likely to report being diagnosed with depression (adjusted odds ratio $\left[\mathrm{OR}_{\text {adj }}\right]=3.42,95 \%$ confidence interval $[\mathrm{CI}]=2.80,4.17)$, anxiety $\left(\mathrm{OR}_{\text {adj }}=\right.$ $3.18,95 \% \mathrm{CI}=2.28,4.43)$, and both depression and anxiety disorders $\left(\mathrm{OR}_{\text {adj }}=5.40,95 \% \mathrm{CI}=4.45,6.56\right)$. Males who reported sexual violence victimization, when compared with males who did not report victimization, were more likely to report being diagnosed with depression $\left(\mathrm{OR}_{\mathrm{adj}}=3.11,95 \% \mathrm{CI}=1.39,6.94\right)$, anxiety $\left(\mathrm{OR}_{\mathrm{adj}}=4.75\right.$, $95 \% \mathrm{CI}=1.78,12.69)$, and both depression and anxiety disorders $\left(\mathrm{OR}_{\mathrm{adj}}=4.29,95 \% \mathrm{CI}=2.09,8.82\right)$. Similarly, females who reported sexual violence victimization had higher odds of being diagnosed with depression $\left(\mathrm{OR}_{\text {adj }}=\right.$ $3.49,95 \% \mathrm{CI}=2.85,4.28)$, anxiety $\left(\mathrm{OR}_{\text {adj }}=3.03,95 \% \mathrm{Cd}=\right.$ $1.39,6.94)$, and both depression and anxiety $\left(\mathrm{OR}_{\text {adj }}=\right.$ $5.69,95 \% \mathrm{CI}=4.66,6.94$ ) when compared with females who reported no victimization.

Results from MANOVA analyses suggest that sexual violence victimization, demographic variables, and their interactions had a statistically significant effect on the symptom profile of depression and anxiety (see Table 3 ). Sexual violence victimization along with other demographic variables was associated with changes in the mean number of days with depression and anxiety symptoms among the victimized population when compared with those who reported no victimization. Significant association in sexual violence victimization and gender of the victim was observed. However, the effect size of the demographic measures and their interactions with sexual violence victimization was relatively small (Table 3 ). Comparisons of the reported mean number of days with symptoms of depression and anxiety by both victimized and nonvictimized males and females are shown in Figure 1. Post hoc Scheffe's tests also indicated significant differences in the mean number of days with symptoms of depression and anxiety when victimized males and females were compared with nonvictimized males and females, respectively. 
Table I. Sample Composition ${ }^{\mathrm{a}}$

\begin{tabular}{|c|c|c|c|c|c|c|}
\hline & \multicolumn{2}{|c|}{$\begin{array}{l}\text { Total Sample } \\
(N=61,187)\end{array}$} & \multicolumn{2}{|c|}{$\begin{array}{l}\text { Nonvictimized Sample } \\
\qquad(N=49,626)\end{array}$} & \multicolumn{2}{|c|}{$\begin{array}{l}\text { Victimized Sample } \\
\qquad(N=3,240)\end{array}$} \\
\hline & $n$ & Wtd\% & $n$ & Wtd\% & $n$ & Wtd\% \\
\hline \multicolumn{7}{|l|}{ Gender* } \\
\hline Male & 24,608 & 48.75 & 21,159 & 51.36 & 239 & 11.16 \\
\hline Female & 36,579 & 51.25 & 28,467 & 48.64 & 3,001 & 88.84 \\
\hline \multicolumn{7}{|l|}{ Age groups (years) } \\
\hline $18-24$ & 2,732 & 12.54 & 2,229 & 12.64 & 182 & 16.72 \\
\hline $25-34$ & 7,328 & 16.88 & 6,074 & 17.35 & 543 & 21.58 \\
\hline $35-44$ & 10,540 & 18.74 & 8,663 & 19.01 & 770 & 22.34 \\
\hline $45-54$ & 13,492 & 18.84 & 10,985 & 19.13 & 888 & 21.45 \\
\hline $55-64$ & 12,086 & 14.20 & 10,004 & 14.40 & 646 & 13.24 \\
\hline $65+$ & 15,009 & 18.81 & 1,167 & 17.47 & 220 & 4.67 \\
\hline \multicolumn{7}{|l|}{ Race/ethnicity } \\
\hline White & 46,103 & 73.74 & 37,754 & 74.89 & 2,539 & 79.93 \\
\hline Black & 4,290 & 7.31 & 3,387 & 7.01 & 162 & 5.62 \\
\hline Hispanics & 3,703 & 11.85 & 2,894 & 11.39 & 159 & 6.72 \\
\hline Others & 6,301 & 7.10 & 5,056 & 6.71 & 349 & 7.73 \\
\hline \multicolumn{7}{|l|}{ Marital status } \\
\hline Single & 7,920 & 16.83 & 6,425 & 16.99 & 480 & 18.84 \\
\hline Married & 36,139 & 65.56 & 30,222 & 67.04 & 1,494 & 52.23 \\
\hline Divorced/separated & 16,885 & 17.62 & 12,856 & 15.98 & 1,253 & 28.93 \\
\hline \multicolumn{7}{|l|}{ Income (\$ per annum) } \\
\hline$\leq 25,000$ & 14,083 & 23.11 & 10,712 & 21.00 & 1,051 & 31.26 \\
\hline $25,000-50,000$ & 16,598 & 30.30 & 13,807 & 30.16 & 872 & 30.44 \\
\hline$>50,000$ & 22,117 & 46.59 & 19,252 & 48.84 & 1,028 & 38.31 \\
\hline \multicolumn{7}{|l|}{ Education } \\
\hline High school or less & 24,152 & 39.74 & 18,969 & 37.95 & 1,003 & 36.44 \\
\hline More than high school & 36,837 & 60.26 & 30,569 & 62.05 & 2,234 & 63.56 \\
\hline \multicolumn{7}{|c|}{ Depression and anxiety diagnostic categories* } \\
\hline Depression only & 5,034 & 7.73 & 4,101 & 7.39 & 632 & 18.82 \\
\hline Anxiety only & 2,367 & 4.05 & 1,925 & 3.75 & 249 & 8.37 \\
\hline Both depression and anxiety & 4,301 & 6.92 & 3,137 & 6.00 & 897 & 28.28 \\
\hline None & 45,918 & 81.03 & 40,226 & 82.86 & 1,434 & 44.52 \\
\hline
\end{tabular}

Note: $\mathrm{Wtd} \%$ = weighted percentage.

a. Frequency for individual categories may not add up to the total $N$ due to missing data.

*Differences between victimized and nonvictimized groups are statistically significant: $p<.05$.

\section{Discussion}

The current study examined the associations between depression and anxiety symptom profiles among victims of sexual violence using data from two BRFSS topicspecific modules. This study estimated the prevalence of depression and anxiety disorders among victimized and nonvictimized adult populations. Overall, our results identify that the prevalence of depression and anxiety disorders among victims of sexual violence is significantly higher when compared with the nonvictimized population. Additionally, strong associations between depression and anxiety disorder and sexual violence victimization were observed when controlling for demographic variables and other potential confounders. The prevalence of depression and anxiety disorders among the victimized and nonvictimized samples was comparable with those reported in previous studies (Fergusson et al., 2002; Walker et al., 2005a).

Depression and anxiety disorders are among the most prevalent psychological disorders in the general population. In a nationally representative sample of U.S. adults, $28.8 \%$ reported experiencing significant anxiety symptoms and $20.8 \%$ of U.S. adults reported experiencing significant symptoms of depression (Kessler, Berglund, Demler, Jin, \& Walters, 2005). Our results identified 


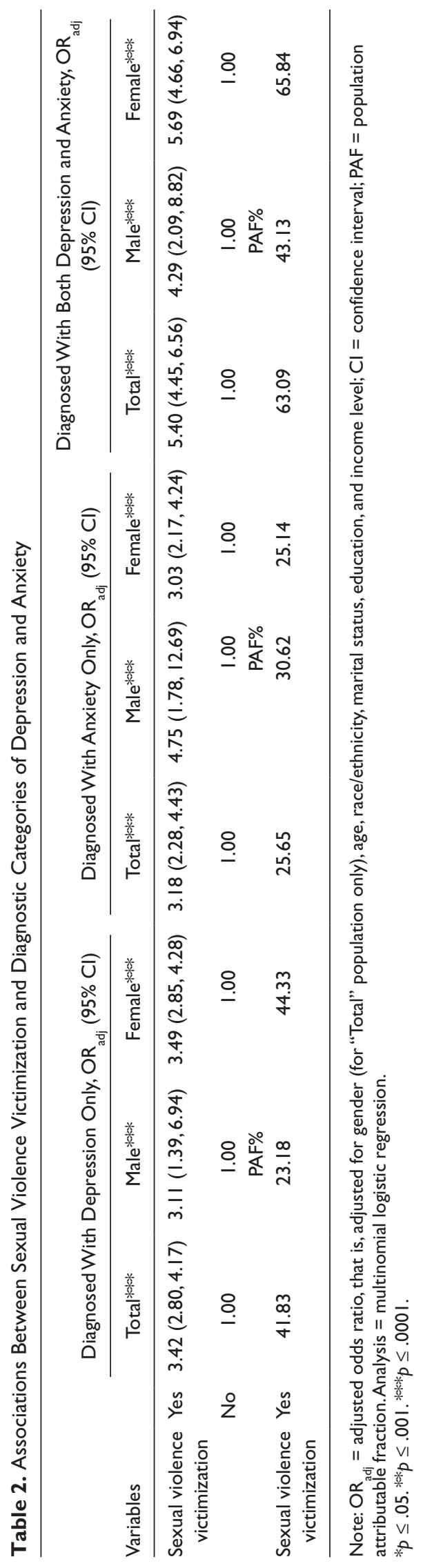


Table 3. Effect of Sexual Violence Victimization and Key Demographic Variables on Depression and Anxiety Symptom Profile

\begin{tabular}{|c|c|c|c|c|c|}
\hline Effect & Wilks' Lambda & F Statistics & $d f$ & $p$ Value & $\eta^{2}$ \\
\hline Sexual violence victimization & .989 & 65.92 & 8,48400 & $<.0001$ & .011 \\
\hline Gender & .998 & 8.24 & 8,48400 & $<.0001$ & .002 \\
\hline Age & .993 & 7.33 & 40,210974 & $<.0001$ & .001 \\
\hline Race/ethnicity & .995 & 9.88 & 24,140375 & $<.0001$ & .002 \\
\hline Marital status & .993 & 20.33 & 16,96800 & $<.0001$ & .0035 \\
\hline Education & .982 & 104.64 & 8,48400 & $<.0001$ & .018 \\
\hline Sexual violence victimization $\times$ Sex & .999 & 4.63 & 8,48400 & $<.0001$ & .001 \\
\hline Sexual violence victimization $\times$ Age & .997 & 2.67 & 40,210974 & $<.0001$ & .0006 \\
\hline Sexual violence victimization $\times$ Race/ethnicity & .998 & 3.92 & 24,140375 & $<.0001$ & .001 \\
\hline Sexual violence victimization $\times$ Marital status & .998 & 4.04 & 16,96800 & $<.0001$ & .0006 \\
\hline
\end{tabular}

Note: Analysis = multivariate analysis of variance (MANOVA).

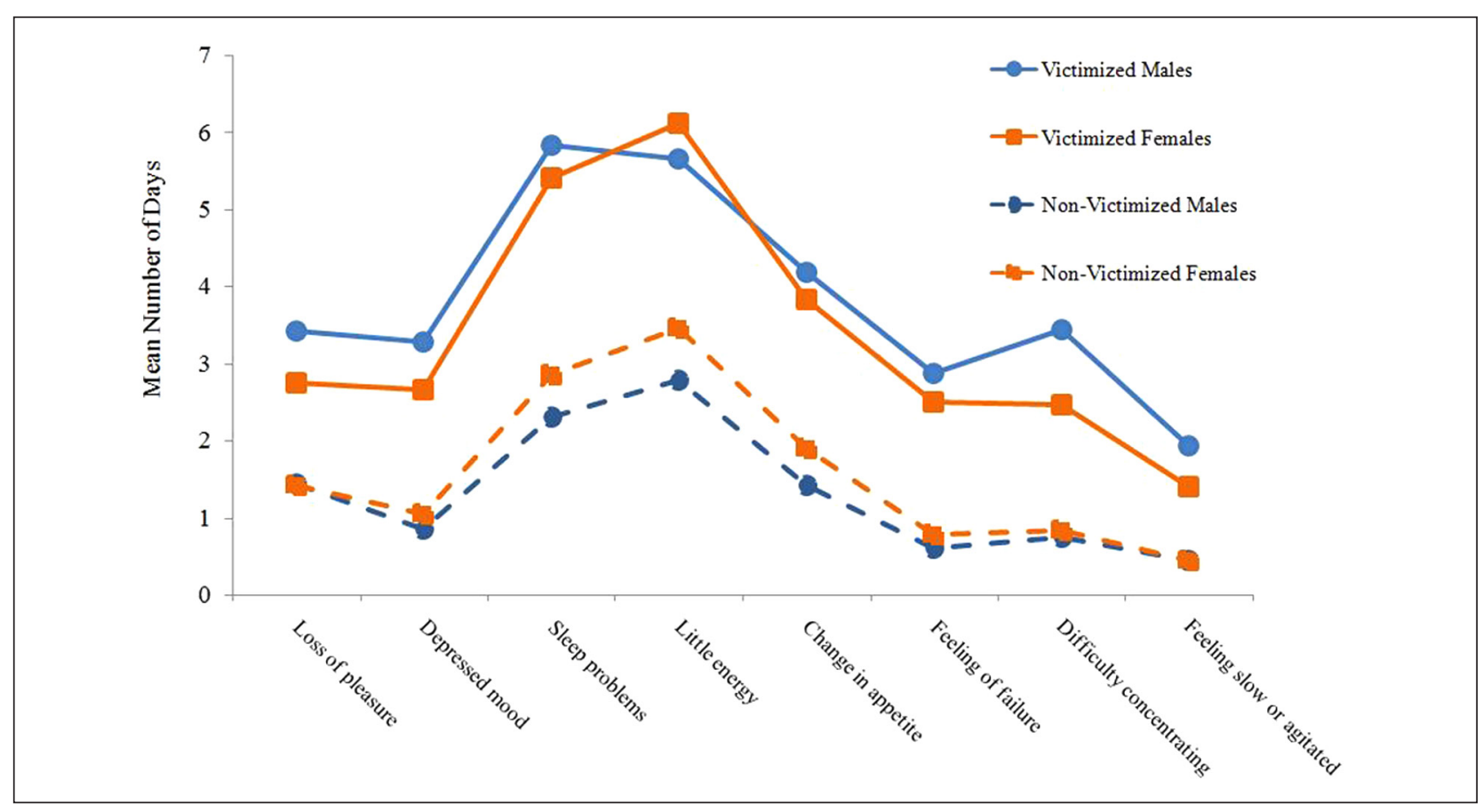

Figure I. Depression and anxiety symptom profile of victimized and nonvictimized males and females

higher prevalence of depression and anxiety disorder among both males and females who experienced sexual violence victimization when compared with nonvictimized participants. Consistent with previous findings, a higher prevalence of self-reported diagnosis and average number of days with symptoms of depression and anxiety among victimized females suggest an association between poor mental health and sexual violence victimization (Cortina \& Kubiak, 2006; Fergusson et al., 2002; Walker et al., 2005a). The current study identified a similar relationship between depression and anxiety symptoms among victimized males using population based data.
Sexual violence victimization has been associated with a variety of adverse mental health consequences in previous studies (Choudhary et al., 2008; Santiago et al., 1985; Walker et al., 2005a). The prevalence of a diagnosis of depression, anxiety, and both depression and anxiety disorders was higher among victimized males and females when compared with those reporting no victimization. A higher prevalence of internalizing behaviors, such as those associated with depression and anxiety disorders, have been previously reported among female victims of sexual violence (Cortina \& Kubiak, 2006; Fergusson et al., 2002), and our findings support these observations. However, 
in previous studies the prevalence of adverse mental health experiences among male victims of sexual violence has not been extensively studied or compared with the prevalence of mental health indicators among similarly victimized females. Results from this study identified a greater prevalence of depression and anxiety disorders among victimized males when compared with nonvictimized males. Although the overall prevalence was lower among male victims when compared with females, the prevalence of depression and anxiety disorders among victimized males suggests that adverse life experience, like sexual violence, may be associated with an increase in internalizing behaviors regardless of gender (Norris \& Feldman-Summers, 1981; Resick, 1993).

An association between sexual violence and a combined symptom profile of depression and anxiety among both males and females that is consistent with previous studies (Schwartz, 1991; Street, Gradus, Stafford, \& Kelly, 2007) were observed. Symptoms like insomnia or excessive sleeping, change in appetite, depressed mood, little energy, and feelings of failure are standard diagnostic criteria used to assess the presence of depression and anxiety disorders (Gilbody, Richards, Brealey, \& Hewitt, 2007). Overall, the self-reported average number of days with symptoms of depression and anxiety disorders was higher among both male and female victims when compared with those reporting no victimization. Existing research suggests that both male (Tewksbury, 2007) and female (Davies, Pollard, \& Archer, 2006) victims of sexual assault are significantly more likely to report poor mental health, including lack of sleep, loss of appetite, feelings of failure, and aggressive behavior.

In addition to the higher prevalence of symptoms of depression and anxiety disorders, self-reported physician or health care professional diagnoses of depression and anxiety disorders were also strongly associated with sexual violence victimization independent of gender. Similar findings were reported by studies using clinical samples of sexual violence victims (King \& Woollett, 1997; Walker et al., 2005a). The identification of consistent findings in a population-based sample strengthens support for the hypothesis that depression and anxiety disorders are more prevalent among victims of sexual violence and highlights the importance of population-based analysis to supplement and extend clinically-based studies.

The results of present study provide important insight into sexual violence victimization and associations with depression and anxiety but are subject to several limitations. Despite weighting to adjust for sampling design and survey nonresponse, estimates calculated as part of this study used data obtained from a subsample of states may not be representative of total U.S. population. Also, questions in the BRFSS modules assessing depression and anxiety differ from other commonly used measures of anxiety (Beck, Epstein, Brown, \& Steer, 1988). These differences may affect item response and may have influenced comparisons with results from other studies. Reports of victimization are based on self-reports and have not been corroborated using external data sources. Furthermore, the eight-symptom BRFSS module assessed a limited number of anxiety-related phenomena and did not address outcomes that have previously been associated with trauma, such as hyperarousal, nightmares, or avoidance of trauma-related stimuli (Beck et al., 1988; Breslau $\&$ Anthony, 2007). Finally, our results are based on crosssectional data testing associations between self-reported victimization and poor mental health indicators and cannot determine causality.

Nationally representative survey data can be used to provide a broader understanding of mental health consequences that may be associated with sexual violence victimization. These results expand the current literature by providing support of the mental health problems associated with sexual victimization in a nationally representative population. This study is an example of an analytic approach that addresses a public health priority area like sexual violence by drawing on data from multiple topicspecific BRFSS modules. The use of publicly available population-based data sources such as BRFSS can help estimate the prevalence of potentially underreported and stigmatizing public health problems like sexual violence and can be used to enhance understanding of associated poor physical and mental health.

The findings of this study highlight the need for a better understanding of male sexual assault. Priorities for future studies might include the epidemiology of male sexual assault; more nuanced understandings of the emotional, physical, and psychological consequences of sexual violence victimization; and the development of targeted interventions informed by understanding of gender differences in definitions of sexual assault. Future studies are urged to use available data sources from multiple sources to enhance understanding of comparatively rare events such as male sexual assault.

\section{Declaration of Conflicting Interests}

The author(s) declared no potential conflicts of interest with respect to the research, authorship, and/or publication of this article.

\section{Funding}

The author(s) disclosed receipt of the following financial support for the research, authorship, and/or publication of this article: This research was supported, in part, by grant \#5R49CE001170 from the National Center for Injury Prevention and Control, CDC, to the West Virginia University Injury Control Research Center. Contents are solely the 
responsibility of the authors and do not represent official views of the CDC.

\section{References}

Afifi, T. O., Macmillan, H., Cox, B. J., Asmundson, G. J., Stein, M. B., \& Sareen, J. (2009). Mental health correlates of intimate partner violence in marital relationships in a nationally representative sample of males and females. Journal of Interpersonal Violence, 24, 1398-1417.

Amstadter, A. B., McCauley, J. L., Ruggiero, K. J., Resnick, H. S., \& Kilpatrick, D. G. (2008). Service utilization and help seeking in a national sample of female rape victims. Psychiatric Services, 59, 1450-1457.

Beck, A. T., Epstein, N., Brown, G., \& Steer, R. A. (1988). An inventory for measuring clinical anxiety: Psychometric properties. Journal of Consulting and Clinical Psychology, 56, 893-897.

Breslau, N., \& Anthony, J. C. (2007). Gender differences in the sensitivity to posttraumatic stress disorder: An epidemiological study of urban young adults. Journal of Abnormal Psychology, 116, 607-611.

Centers for Disease Control and Prevention. (2006). Behavioral Risk Factor Surveillance System Survey data. Atlanta, GA: Author.

Choudhary, E., Coben, J., \& Bossarte, R. (2008). Gender and time differences in the associations between sexual violence victimization, health outcomes, and risk behaviors. American Journal of Men's Health, 2, 254-259.

Cortina, L. M., \& Kubiak, S. P. (2006). Gender and posttraumatic stress: Sexual violence as an explanation for women's increased risk. Journal of Abnormal Psychology, 115, 753-759.

Davies, M., Pollard, P., \& Archer, J. (2006). Effects of perpetrator gender and victim sexuality on blame toward male victims of sexual assault. Journal of Social Psychology, 146, 275-291.

Fergusson, D. M., Swain-Campbell, N. R., \& Horwood, L. J. (2002). Does sexual violence contribute to elevated rates of anxiety and depression in females? Psychological Medicine, 32, 991-996.

Gilbody, S., Richards, D., Brealey, S., \& Hewitt, C. (2007). Screening for depression in medical settings with the Patient Health Questionnaire (PHQ): A diagnostic meta-analysis. Journal of General Internal Medicine, 22, 1596-1602.

Hedtke, K. A., Ruggiero, K. J., Fitzgerald, M. M., Zinzow, H. M., Saunders, B. E., Resnick, H. S., \& Kilpatrick, D. G. (2008). A longitudinal investigation of interpersonal violence in relation to mental health and substance use. Journal of Consulting and Clinical Psychology, 76, 633-647.

Kaminer, D., Grimsrud, A., Myer, L., Stein, D. J., \& Williams, D. R. (2008). Risk for post-traumatic stress disorder associated with different forms of interpersonal violence in South Africa. Social Science \& Medicine, 67, 1589-1595.

Kessler, R. C., Berglund, P., Demler, O., Jin, R., \& Walters, E. E. (2005). Lifetime prevalence and age-of-onset distributions of DSM-IV disorders in the National Comorbidity Survey replication. Archives of General Psychiatry, 62, 593-602.

King, M., \& Woollett, E. (1997). Sexually assaulted males: 115 men consulting a counseling service. Archives of Sexual Behavior, 26, 579-588.

Kroenke, K., Spitzer, R. L., \& Williams, J. B. (2001). The PHQ9: Validity of a brief depression severity measure. Journal of General Internal Medicine, 16, 606-613.

Leserman, J. (2005). Sexual abuse history: Prevalence, health effects, mediators, and psychological treatment. Psychosomatic Medicine, 67, 906-915.

Mechanic, M. B., Weaver, T. L., \& Resick, P. A. (2008). Mental health consequences of intimate partner abuse: A multidimensional assessment of four different forms of abuse. Violence Against Women, 14, 634-654.

Messman-Moore, T. L., Brown, A. L., \& Koelsch, L. E. (2005). Posttraumatic symptoms and self-dysfunction as consequences and predictors of sexual revictimization. Journal of Traumatic Stress, 18, 253-261.

Norris, J., \& Feldman-Summers, S. (1981). Factors related to the psychological impacts of rape on the victim. Journal of Abnormal Psychology, 90, 562-567.

Rand, M. R. (2008). Criminal victimization, 2007 (No. NCJ 224390). Washington, DC: U.S. Department of Justice, Bureau of Justice Statistics.

Reid, R. J., Bonomi, A. E., Rivara, F. P., Anderson, M. L., Fishman, P. A., Carrell, D. S., \& Thompson, R. S. (2008). Intimate partner violence among men prevalence, chronicity, and health effects. American Journal of Preventive Medicine, 34, 478-485.

Rentoul, L., \& Appleboom, N. (1997). Understanding the psychological impact of rape and serious sexual assault of men: A literature review. Journal of Psychiatric and Mental Health Nursing, 4, 267-274.

Resick, P. A. (1993). The psychological impact of rape. Journal of Interpersonal Violence, 8, 223-255.

Santiago, J. M., McCall-Perez, F., Gorcey, M., \& Beigel, A. (1985). Long-term psychological effects of rape in 35 rape victims. American Journal of Psychiatry, 142, 1338-1340.

Schwartz, I. L. (1991). Sexual violence against women: Prevalence, consequences, societal factors, and prevention. American Journal of Preventive Medicine, 7, 363-373.

Street, A. E., Gradus, J. L., Stafford, J., \& Kelly, K. (2007). Gender differences in experiences of sexual harassment: Data from a male-dominated environment. Journal of Consulting and Clinical Psychology, 75, 464-474.

Tewksbury, R. (2007). Effects of sexual assaults on men: Physical, mental and sexual consequences. International Journal of Men's Health, 6, 22-35.

Tjaden, P., \& Thoennes, N. (2006). Extent, nature, and consequences of rape victimization: Findings from the national violence against women survey (No. NCJ 210346). 
Washington, DC: U.S. Department of Justice, National Institute of Justice.

Ullman, S. E., Filipas, H. H., Townsend, S. M., \& Starzynski, L. L. (2007). Psychosocial correlates of PTSD symptom severity in sexual assault survivors. Journal of Traumatic Stress, 20, 821-831.
Walker, J., Archer, J., \& Davies, M. (2005a). Effects of male rape on psychological functioning. British Journal of Clinical Psychology, 44, 445-451.

Walker, J., Archer, J., \& Davies, M. (2005b). Effects of rape on men: A descriptive analysis. Archives of Sexual Behavior, 34, 69-80. 